\title{
BMJ Open Are payment methods for prescription drugs associated with polypharmacy in older adults in Ireland? Evidence from the TILDA cohort study
}

\author{
Aine Varley (D) , ${ }^{1}$ John Cullinan ${ }^{2}$
}

To cite: Varley A, Cullinan J. Are payment methods for prescription drugs associated with polypharmacy in older adults in Ireland? Evidence from the TILDA cohort study. BMJ Open 2020;10:e036591. doi:10.1136/ bmjopen-2019-036591

- Prepublication history for this paper is available online. To view these files, please visit the journal online (http://dx.doi. org/10.1136/bmjopen-2019036591).

Received 23 December 2019 Revised 26 August 2020 Accepted 02 September 2020

Check for updates

(c) Author(s) (or their employer(s)) 2020. Re-use permitted under CC BY-NC. No commercial re-use. See rights and permissions. Published by BMJ.

${ }^{1}$ Department of Pharmacology and Therapeutics, Trinity College Dublin, Dublin, Ireland

${ }^{2}$ Discipline of Economics, National University of Ireland Galway, Galway, Ireland

Correspondence to Dr Aine Varley; varleyai@tcd.ie

\section{ABSTRACT}

Objectives Polypharmacy is commonly defined as the use of five or more medications, is associated with a range of adverse outcomes and is particularly common in older adults. We sought to examine the relationship between polypharmacy and payment methods for prescription drugs among older adults in Ireland.

Methods This is a cross-sectional analysis of data from wave 3 of The Irish Longitudinal Study on Aging, a nationally representative cohort study sample of community-living adults aged 50 years and older in Ireland. We used multivariable logistic regression to model the independent relationship between polypharmacy and drug payment methods. We controlled for a wide range of demographic, socioeconomic and health-related variables. Results Enrolment in publicly funded schemes which entitle participants to subsidised or free prescription medications was independently associated with increased odds of reporting polypharmacy. Relative to out-of-pocket payment, we found polypharmacy was independently associated with payment via medical card (OR 2.65; 95\% $\mathrm{Cl} 2.13$ to 3.28 ), drugs payment scheme (OR $3.83 ; 95 \% \mathrm{Cl}$ 2.96 to 4.95$)$, long-term illness scheme (OR 4.24; $95 \% \mathrm{Cl}$ 3.06 to 5.87 ), but not private health insurance (OR 0.82 ; $95 \% \mathrm{Cl} 0.42$ to 1.62 ).

Conclusions Given multiple payment methods available for funding prescription charges in Ireland, there is a significant differential in the upfront costs faced by patients. One implication of our results is that the quantity of medications consumed by an individual may be influenced by payment methods for prescription fees. This could lead to overconsumption of medicines by those who are covered, or underconsumption by those who are not. However, our study was limited by an inability to discriminate between appropriate and inappropriate polypharmacy or to account for differential levels of multimorbidity, suggesting further research on this topic is warranted.

\section{INTRODUCTION}

Polypharmacy involves the administration of more medicines than are clinically indicated, representing unnecessary drug use, and has been described as a 'serious and significant public health challenge'. ${ }^{2}$ While there is no consensus on how best to operationalise the

\section{Strengths and limitations of this study}

- This is the first Irish study to evaluate the relationship between polypharmacy and the payment method used to fund prescription medications in older adults, while controlling for socioeconomic and health-related factors.

- We use data from a large nationally representative cohort study of older people that collects information on a range of individual, socioeconomic and health-related variables.

- Data collection was undertaken by trained professionals in the participants' home environment, which is particularly important for accurately quantifying medication use.

- Limitations of this study include an inability to distinguish between appropriate and inappropriate polypharmacy or to account for differential levels of multimorbidity.

definition, the most commonly used criteria describe polypharmacy as the concomitant use of five or more medications, with extreme polypharmacy considered the use of 10 or more agents. ${ }^{3}$ Polypharmacy is associated with a number of adverse health outcomes, mediated through adverse drug events, drug-drug interactions, drug-disease interactions, prescribing cascades, as well as non-adherence. ${ }^{45}$ It is particularly problematic in the older population, in whom physiological changes associated with ageing result in impaired drug metabolism and an increased propensity to experience adverse drug events. ${ }^{6}$ Polypharmacy is associated with substantial health-related costs, directly and indirectly, to the individual and to healthcare systems. $^{7-9}$

In terms of predictors, increasing age is associated with polypharmacy, and it is likely that much of the association is attributable to the increased burden of chronic disease that is correlated with advancing age. ${ }^{10-14}$ The presence of one or more chronic health 
conditions is associated with increased likelihood of reporting polypharmacy, and older adults are more likely to be diagnosed with multiple conditions. ${ }^{15-17}$ In Ireland, the context for our study, previous waves of The Irish Longitudinal Study on Aging (TILDA) reported that $19 \%$ of adults aged $\geq 50$ years met the criteria for polypharmacy, rising to $31 \%$ in those aged over 65 years and $37 \%$ in those aged over 75 years. ${ }^{18}$ This is important given that population projections predict a large demographic shift in the coming decades, with significantly increased numbers of older adults living globally. ${ }^{19}{ }^{20}$ For example, the number of people aged over 65 years in Ireland is expected to increase from 629800 in 2016 to 1.6 million in 2051, with the very old population (those aged over 80 years) set to increase from 147800 to at least 535900 over the same period. ${ }^{21}$

As well as ageing and health, socioeconomic factors also appear to be associated with polypharmacy, with large observational studies reporting that lower education, lower wealth and increased deprivation are all associated with higher rates of polypharmacy, independent of disease burden and demographic factors. ${ }^{10} 111422$ Obesity and alcohol consumption have additionally been found to be correlated with polypharmacy, independent of socioeconomic factors. ${ }^{11}$

Within this context, it is noteworthy that financial incentives appear to play a role in healthcare utilisation among adults living in Ireland. Nolan and Smith examined the effect of payment method on general practitioner (GP) visits and found those who face higher out-of-pocket (OOP) costs visited less frequently than those entitled to free care. ${ }^{23}$ Similarly, Ma and Nolan found that changes in eligibility for free GP care for older adults resulted in a $43 \%$ increase in annual visits when free care was introduced, and a $29 \%$ decrease when eligibility was withdrawn. ${ }^{24}$ In terms of prescription drug use, a recent analysis of pharmacy claims data in Ireland reported that $64.3 \%$ of adults aged $\geq 45$ years eligible for heavily subsidised prescription costs met criteria for polypharmacy in at least 1 month in $2013{ }^{25}$ However, this study did not adjust for socioeconomic or health-related factors. To date, we have not identified any analysis, either for Ireland or internationally, which examines the relationship between the payment methods used to fund prescription drugs and polypharmacy, while accounting for potential socioeconomic and health-related confounding factors.

Funding for healthcare in Ireland comes from a complex mix of both public and private sources and this is reflected in the range of payment methods available for prescription charges. Persons resident in Ireland may qualify for either full eligibility (category 1 ) or limited eligibility (category 2) for health services. Details of the five most commonly used payment methods for prescription fees in Ireland are outlined in table 1. Briefly, two schemes operate under category 1-the medical card (MC) and long-term illness (LTI) schemes. These entitle participants to heavily subsidised or free prescriptions. Individuals eligible for category 2 may enrol in the publicly funded drugs payment scheme (DPS), which entitles them to household prescription fees which are capped at a set monthly cost. Alternatively, individuals can enrol in private health insurance (PHI) programmes, which may cover prescription fees, or bear the full OOP cost. Three of the schemes (MC, LTI and DPS) operate under the remit of the Primary Care Reimbursement Service (PCRS), which funds and collects data on the prescriptions dispensed under these schemes.

As a result of the multiple payment methods available for funding prescription charges in Ireland, there is a significant differential in the upfront costs faced by patients. This paper investigates if the cost differential in prescription charges can help explain the issue of

\begin{tabular}{|c|c|c|c|}
\hline Category & Scheme & Details & Eligibility \\
\hline \multirow[t]{2}{*}{1} & Medical card & $\begin{array}{l}\text { Prescription fees at } € 2.50 \text { per item, } \\
\text { capped at } € 25 \text { per month per individual/ } \\
\text { household*. }\end{array}$ & $\begin{array}{l}\text { Means tested (income-based } \\
\text { assessment) }\end{array}$ \\
\hline & Long-term illness scheme & Entitles participants to free prescriptions. & $\begin{array}{l}\text { Confirmed diagnosis of one } \\
\text { of a number of prespecified } \\
\text { chronic health conditions }\end{array}$ \\
\hline \multirow[t]{3}{*}{2} & Drugs payment scheme & $\begin{array}{l}\text { Prescription fees capped at } € 144 \text { per } \\
\text { month for each individual/household*. }\end{array}$ & All citizens eligible \\
\hline & $\begin{array}{l}\text { Full out-of-pocket } \\
\text { payment }\end{array}$ & $\begin{array}{l}\text { Full cost of prescription fees paid privately } \\
\text { by an individual/household. }\end{array}$ & $\mathrm{N} / \mathrm{A}$ \\
\hline & $\begin{array}{l}\text { Private health insurance } \\
\text { reimbursement }\end{array}$ & $\begin{array}{l}\text { Certain private health insurance schemes } \\
\text { offer reimbursement for a portion of } \\
\text { prescription charges incurred by an } \\
\text { individual. }\end{array}$ & $\mathrm{N} / \mathrm{A}$ \\
\hline
\end{tabular}

Source: Health Service Executive, Ireland.

*Denotes prescription fees and caps at the time of collection of The Irish Longitudinal Study on Aging (TILDA) wave 3 data (2014-2015). N/A, not applicable. 
polypharmacy in older adults in Ireland. Our objective is to evaluate the relationship between the likelihood of reporting polypharmacy and the payment method used for prescription medications by older adults in Ireland, while controlling for a range of demographic, socioeconomic and health-related factors.

\section{DATA AND METHODS \\ Data}

We use data from wave 3 of TILDA, ${ }^{26}$ a nationally representative cohort study of community-dwelling adults aged over 50 years living in the Republic of Ireland. Information is collected on a broad range of domains including health status, healthcare utilisation, demographic, social and economic circumstances. Study design and methodology is described in detail elsewhere. ${ }^{27}$ Initial recruitment took place between 2009 and 2011, with subsequent follow-up completed on a biannual basis. Data collection for the TILDA study is undertaken by trained professional social interviewers via computer-aided personal interviewing. Participants are also invited to complete a self-completion questionnaire and undergo a physical examination with a dedicated, trained study nurse. ${ }^{28}$ At the time of preparing this article, wave 3 was the most recent publicly available set of data and had collected information on 6400 individuals.

\section{Variables}

The dependent variable of interest is a binary variable which indicates if an individual reports polypharmacy, defined as the use of $\geq 5$ medications. Medication use was assessed as part of the TILDA interview by a trained interviewer. Participants were required to provide the interviewer with details of all medications that they take on a regular basis, which were subsequently subcategorised as prescription medications, non-prescription medications or supplements. For the purpose of this analysis, polypharmacy is defined as the consumption of $\geq 5$ medications from all subcategories (prescription, non-prescription medications and supplements). Binary variables defining polypharmacy excluding supplements ( $\geq 5$ regular medications when supplement use is excluded), extreme polypharmacy ( $\geq 10$ medications) and extreme polypharmacy excluding supplements are also available from the TILDA data set.

The main independent variable of interest is a categorical variable indicating the payment method used by an individual in purchasing their last prescription. The participant was asked to select one of five options: they purchased using OOP payment; their prescription charges were covered under the MC scheme; they paid using the DPS; they received reimbursement from a PHI scheme; or they received free prescriptions through the LTI scheme. Control variables include information on demographic factors, socioeconomic status, health status and healthcare utilisation (see table 2). Selection of these variables was based on a review of the existing literature on determinants of polypharmacy, as well as the availability of variables within the TILDA data set.

\section{Analysis}

Summary statistics for all of the variables considered were calculated. Univariate logistic regression models were estimated to evaluate the relationship between polypharmacy and each of the individual independent variables (see online supplemental appendix table A0). All variables analysed in the univariate models were included in the multivariable regression analysis, and we estimated multivariable logistic regression models of the relationship between polypharmacy and payment method for prescription charges, controlling for demographic factors, socioeconomic factors, health status and healthcare utilisation. The results from these models are presented as estimated ORs. This provides, for each covariate, the odds of polypharmacy for one category of the covariate relative to another category, adjusting for all other covariates in the model. No imputation methods were used for missing data, which was trivial—see table 2. Overall model significance was assessed using likelihood ratio tests. Individual parameter significance was assessed using Wald tests. McFadden's pseudo- $\mathrm{R}^{2}$ was used to test for model goodness of fit.

A range of additional models were estimated to assess the sensitivity and robustness of our main findings. We estimated models using alternative dependent variables (ie, 'polypharmacy excluding supplements', 'extreme polypharmacy' and 'extreme polypharmacy excluding supplements'), as well as models containing different subsets of the explanatory variables. In particular, sensitivity analysis excluding the variables relating to healthcare utilisation was conducted. All analyses were performed using Stata V.15.1 (StataCorp).

\section{Patient and public involvement}

No patients were involved in the conduct of this analysis.

\section{RESULTS}

\section{Summary statistics}

Summary statistics for all variables included in our analysis are presented in table 2 .

\section{Polypharmacy}

The overall prevalence of polypharmacy in the sample was $25.8 \%$. When supplement use was excluded, the prevalence was $23.0 \%$. The prevalence of extreme polypharmacy was $4.0 \%$, and $2.9 \%$ when supplement use was excluded.

\section{Payment method}

When asked how their most recently dispensed prescription was funded, the highest proportion of participants reported using MCs $(44.8 \%)$, OOP payments $(35.6 \%)$ and the DPS (11.0\%). Figure 1 shows the proportion of individuals who reported polypharmacy by the payment method used. Polypharmacy was most common in 
Table 2 Variable definitions and sample descriptive statistics

\begin{tabular}{|c|c|c|c|}
\hline Variable & Definition & Categories & $\mathrm{n}(\%)$ or mean (SD) \\
\hline \multirow[t]{2}{*}{ Polypharmacy } & \multirow[t]{2}{*}{ Use of five or more medications } & Yes & $1654(25.8 \%)$ \\
\hline & & No & $4746(74.2 \%)$ \\
\hline Extreme polypharmacy & Use of 10 or more medications & No & $6146(96.0 \%)$ \\
\hline $\begin{array}{l}\text { Polypharmacy excluding } \\
\text { supplements }\end{array}$ & $\begin{array}{l}\text { Use of five or more medications, excluding } \\
\text { supplements }\end{array}$ & Yes & $1469(23.0 \%)$ \\
\hline \multirow{2}{*}{$\begin{array}{l}\text { Extreme polypharmacy } \\
\text { excluding supplements }\end{array}$} & \multirow{2}{*}{$\begin{array}{l}\text { Use of } 10 \text { or more medications, excluding } \\
\text { supplements }\end{array}$} & Yes & $187(2.9 \%)$ \\
\hline & & No & $6213(97.1 \%)$ \\
\hline \multirow[t]{4}{*}{ Payment method } & \multirow[t]{4}{*}{ How was last prescription paid for? } & OOP & $2281(35.6 \%)$ \\
\hline & & $\mathrm{MC}$ & $2869(44.8 \%)$ \\
\hline & & DPS & $706(11.0 \%)$ \\
\hline & & Missing & $112(1.8 \%)$ \\
\hline Age & Respondent's age at time of interview & Years & $66.4( \pm 8.9)$ \\
\hline \multirow[t]{2}{*}{ Sex } & \multirow[t]{2}{*}{ Sex of respondent } & Male & $2825(44.1 \%)$ \\
\hline & & Female & $3575(55.9 \%)$ \\
\hline \multirow[t]{4}{*}{ Education } & \multirow[t]{4}{*}{ Highest level of education achieved } & Primary & $1623(25.4 \%)$ \\
\hline & & Secondary & $2548(39.8 \%)$ \\
\hline & & Higher & $2228(34.8 \%)$ \\
\hline & & Missing & $1(0.02 \%)$ \\
\hline Employment & Current employment status & Employed & $2111(33.0 \%)$ \\
\hline \multirow[t]{3}{*}{ Obesity } & \multirow[t]{3}{*}{ Is respondent's BMI $>30 \mathrm{~kg} / \mathrm{m}^{2} ?$} & Yes & $1368(21.4 \%)$ \\
\hline & & No & $4809(75.1 \%)$ \\
\hline & & Missing & $223(3.5 \%)$ \\
\hline \multirow[t]{6}{*}{ Self-rated health } & \multirow[t]{6}{*}{ Respondent's rating of own health } & Excellent & $910(14.2 \%)$ \\
\hline & & Very good & $2140(33.4 \%)$ \\
\hline & & Good & $2187(34.2 \%)$ \\
\hline & & Fair & $952(14.9 \%)$ \\
\hline & & Poor & $210(3.3 \%)$ \\
\hline & & Missing & $1(0.02 \%)$ \\
\hline \multirow[t]{3}{*}{ Chronic illness } & \multirow{3}{*}{$\begin{array}{l}\text { Does the respondent have any long-term } \\
\text { illness or disability? }\end{array}$} & Yes & $2718(42.5 \%)$ \\
\hline & & No & 3678 (57.5\%) \\
\hline & & Missing & $4(0.1 \%)$ \\
\hline
\end{tabular}

Continued 


\begin{tabular}{lllr}
\hline Table 2 Continued & & & \\
\hline Variable & Definition & Categories & n (\%) or mean (SD) \\
\hline Primary care usage & How many visits to GP in the last year? & None & $532(8.3 \%)$ \\
& & $1-4$ & $4261(66.6 \%)$ \\
& & $5-9$ & $1018(15.9 \%)$ \\
& & $10-14$ & $448(7.0 \%)$ \\
& & $15+$ & $128(2.0 \%)$ \\
Secondary care usage & How many outpatient visits in the last year? & None & $3(0.2 \%)$ \\
& & 1 & $3606(56.3 \%)$ \\
& & $2+$ & $1173(18.3 \%)$ \\
\end{tabular}

Source: Analysis of The Irish Longitudinal Study on Aging (TILDA) wave 3 data.

BMI, body mass index; DPS, drugs payment scheme; GP, general practitioner; LTI, long-term illness; MC, medical card; OOP, out of pocket; $\mathrm{PHI}$, private health insurance.

individuals who subscribed to the LTI scheme $(44.0 \%)$, followed by MC users (38.8\%) and DPS subscribers $(32.7 \%)$. Of those who received reimbursement via PHI, $9.5 \%$ were recorded as having polypharmacy, as were $6.9 \%$ of those who paid the full OOP cost.

\section{Participant characteristics}

The mean age of the cohort was 66.4 years (SD: 8.9 years); $55.9 \%$ of the sample were female. In terms of highest level of education achieved, $25.4 \%$ had a primary education, $39.8 \%$ a secondary education and $34.8 \%$ a higher education qualification. Overall, $33.0 \%$ of the sample were employed, with $45.4 \%$ retired. Of the cohort, $12.8 \%$ indicated they were smokers, while $21.4 \%$ were measured as obese. When asked to self-rate their health, $81.8 \%$ reported their health was excellent, very good or good, while $42.5 \%$ of participants reported living with at least one chronic illness or disability. Two-thirds of those surveyed reported visiting their GP between one and four

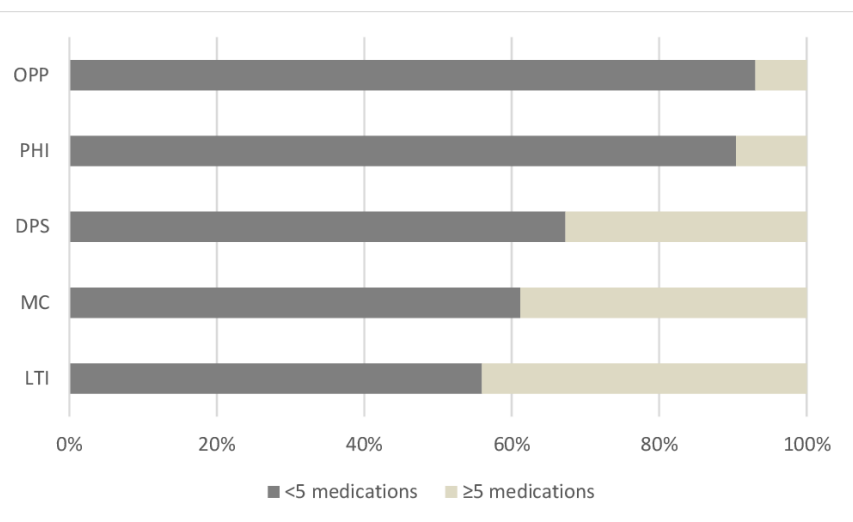

Figure 1 Proportion of respondents experiencing polypharmacy by payment method for most recent prescription. Source: Analysis of The Irish Longitudinal Study on Aging (TILDA) wave 3 data. DPS, drugs payment scheme; LTI, long-term illness; MC, medical card; OPP, out-of-pocket payment; $\mathrm{PHI}$, private health insurance. times in the preceding year, and the majority $(56.3 \%)$ had not attended a hospital outpatient appointment in the same period.

\section{Multivariable regression analysis \\ Payment methods}

The results of our preferred estimated multivariable model are presented in table 3. Following the addition of appropriate control variables, enrolment in the LTI scheme (OR 4.24; 95\% CI 3.06 to 5.87), DPS (OR 3.83; 95\% CI 2.96 to 4.95 ) and using an MC (OR 2.65; $95 \%$ CI 2.13 to 3.28 ) were all independently associated with increased odds of reporting polypharmacy when compared with the base case of OOP payment. There was no statistically significant difference observed for PHI.

\section{Participant characteristics}

As has been demonstrated in previous research, age was strongly associated with polypharmacy (OR 1.07; 95\% CI 1.06 to 1.09). Our estimates imply an extra 10 years of life is associated with approximately double the odds of reporting polypharmacy. There was no statistically significant independent association between polypharmacy and gender. In terms of educational attainment the odds of reporting polypharmacy in those with secondary school education were $19 \%$ lower compared with those who achieved primary school only (OR $0.81 ; 95 \%$ CI 0.68 to 0.96 ), while the OR for tertiary education was not statistically significant. Those who were retired were more likely to report polypharmacy than those currently employed (OR $1.31 ; 95 \%$ CI 1.05 to 1.63 ), as were those who identified in the 'other' employment category (OR 1.68; 95\% CI 1.33 to 2.12). Smoking status was not associated with polypharmacy (OR 1.03; 95\% CI 0.83 to 1.28), while those who were classified as obese had higher rates of polypharmacy than those who were not (OR 1.56; 95\% CI 1.33 to $1.84)$. 
Open access

Table 3 Adjusted ORs of polypharmacy from multivariable logistic regression model

OR

$P$ value

$95 \% \mathrm{Cl}$

Payment method

Full OOP payment $\quad 1.00$

Medical card 2.65

Drugs payment scheme $\quad 3.83$

$65<0.001$

2.13 to 3.28

$3.83<0.001$

2.96 to 4.95

Private health insurance

0.82

0.568

0.42 to 1.62

Long-term illness scheme

4.24

Age

1.07

$<0.001$

3.06 to 5.87

Sex

Male

1.00

Female

1.01

0.907

0.87 to 1.17

Education

Primary

1.00

Secondary

0.81

Third level/higher

0.88

0.017

0.68 to 0.96

Employment

$\begin{array}{lr}\text { Employed } & 1.00 \\ \text { Retired } & 1.31 \\ \text { Other } & 1.68\end{array}$

1.00

1.31

0.015

1.05 to 1.63

Other

1.68

$<0.001$

1.33 to 2.12

Smoking status

Non-smoker 1.00

Smoker 1.03

1.03

0.786

0.83 to 1.28

Obesity status

$\begin{array}{ll}\text { Not obese } & 1.00 \\ \text { Obese } & 1.56\end{array}$

1.00

Self-rated health

1.56

$<0.001$

1.33 to 1.84

Excellent

1.00

Very good

1.08

Good

1.80

0.595

0.82 to 1.46

Fair

2.68

$<0.001$

1.35 to 2.40

Poor

3.87

$<0.001$

1.95 to 3.67

Chronic illness

One or more chronic illnesses

1.00

No chronic illness

0.34

$<0.001$

2.48 to 6.04

GP visits in the last year

\begin{tabular}{|c|c|c|c|}
\hline None & 1.00 & & \\
\hline $1-4$ & 2.08 & 0.001 & 1.37 to 3.16 \\
\hline $5-9$ & 2.54 & $<0.001$ & 1.63 to 3.93 \\
\hline $15+$ & 4.20 & $<0.001$ & 2.32 to 7.63 \\
\hline \multicolumn{4}{|c|}{ OPD visits in the last year } \\
\hline $2+$ & 1.77 & $<0.001$ & 1.50 to 2.09 \\
\hline $\mathrm{n}$ & \multicolumn{3}{|l|}{6042} \\
\hline $\operatorname{LR} \chi^{2}(\mathrm{df})$ & \multicolumn{3}{|l|}{$1999(23)$} \\
\hline Pseudo- $R^{2}$ & \multicolumn{3}{|l|}{0.2901} \\
\hline
\end{tabular}

Source: Analysis of The Irish Longitudinal Study on Aging (TILDA) wave 3 data. 
There was an independent association between polypharmacy and poorer self-rated health. Compared with those who reported excellent health, those with good (OR $1.80 ; 95 \%$ CI 1.35 to 2.40 ), fair (OR 2.68; $95 \%$ CI 1.95 to 3.67 ) and poor (OR 3.87; 95\% CI 2.48 to 6.04 ) health had significantly higher odds of polypharmacy. The absence of chronic health problems was associated with decreased odds of reporting polypharmacy (OR 0.34; $95 \%$ CI 0.30 to 0.40 ). In terms of healthcare utilisation, those who had the highest level of GP visits and outpatient department (OPD) visits had higher relative odds of reporting polypharmacy-4.20 (95\% CI 2.32 to 7.63$)$ and 1.77 (95\% CI 1.50 to 2.09 ), respectively.

\section{Sensitivity analysis and robustness checks}

Sensitivity analysis was performed to evaluate the effect of excluding healthcare utilisation variables from the model. To test for robustness, we estimated models where the dependent variables were polypharmacy excluding supplement use, extreme polypharmacy and extreme polypharmacy excluding supplement use. Results are presented in online supplemental appendix table A1A4. Our overall results and conclusions did not change substantively following the exclusion of healthcare utilisation from the model. When estimating the models using alternative dependent variables, enrolment in the LTI scheme was found to be associated with polypharmacy (both including and excluding supplement use) in a statistically significant manner. However, when the models were estimated using extreme polypharmacy (with and without supplement use) the association with LTI enrolment was not significant at the $5 \%$ level.

\section{DISCUSSION}

\section{Main findings}

Excessive medication use is both harmful and costly and polypharmacy is strongly correlated with advancing age. Given projected shifts in demographic patterns in the coming years, the scale of the problem in Ireland is set to increase unless suitable policies are developed and it follows that these should be guided by appropriate evidence. Here, we evaluate if there is an independent association between polypharmacy and subsidised or free prescriptions in older adults living in Ireland. We find polypharmacy is more common in those who receive free or subsidised medications compared with those who face full OOP charges, even after controlling for demographic, socioeconomic and health-related factors. We did not find any independent association for reimbursement through PHI, though the numbers of participants who were in this category were relatively small (14 participants who reported polypharmacy received reimbursement through a PHI scheme; only three patients who reported extreme polypharmacy received reimbursement through PHI).

A number of mechanisms could contribute to the independent association we have estimated between polypharmacy and the payment method used for prescription costs. It may be that the payment method used directly influences the number of medications a patient consumes, thus affecting their odds of reporting polypharmacy. On the other hand, it may be that a need for more medicines influences the type of payment method an individual is eligible for (ie, reverse causality), although we attempt to control for health status in our model. Finally, it may be that the relationship is instead explained by confounding variables not accounted for in this analysis, though our model does include a wide range of controls.

For example, the socioeconomic gradient in health is well recognised. Those who earn lower incomes and have lower levels of education are frequently found to have poorer health, which in turn is associated with an increased risk of polypharmacy. Many of the subsidisation schemes we evaluated have eligibility criteria based on financial and/or medical needs. Therefore, socioeconomic factors were explicitly considered in order to reduce confounding. Employment status was found to be associated with polypharmacy, with retired individuals more likely to report polypharmacy than those who were employed. Those who identified their employment status as 'other' had higher odds than those in employment of reporting polypharmacy. This group includes individuals who may be unfit for work on the basis of medical grounds or disability and it is possible that this reflects health status. As has been demonstrated in other populations, higher levels of education were associated with lower rates of polypharmacy after controlling for demographic and health factors. ${ }^{14}$ Our results show that those who had secondary education were less likely to report polypharmacy than those who had primary education alone. However, there was no statistically significant difference in polypharmacy for those who had third-level education compared with those with primary education alone.

A number of health-related behaviours that are associated with socioeconomic status and polypharmacy were also included as controls in our analysis. Obesity was found to be associated with higher rates of polypharmacy; it is unclear if this is a direct association or if this is accounting for a health effect not captured elsewhere. Health status is an important independent predictor of polypharmacy. It may also be directly or indirectly related to the payment method used and, therefore, we included a number of variables related to health status and healthcare usage in order to reduce confounding. Individuals who reported relatively poorer health were found to be significantly more likely to report polypharmacy, as expected. Selfreported health status has been found to be a valid tool for discriminating between health states and, in some cases, is predictive of mortality. ${ }^{29-31}$ Our results also show that the presence of at least one chronic illness was associated with a higher probability of reporting polypharmacy, which is also as expected.

Healthcare usage was also included in our model to account for features of poor health not captured in our 
health status variables. In line with a priori expectations, those who had relatively higher numbers of GP visits and outpatient attendances were more likely to report polypharmacy. A potential criticism of the inclusion of health usage markers in our analysis is that medical visits are 'on the causal pathway' of polypharmacy. We re-estimated the multivariable models excluding the variables for GP and OPD visits in the last year (see online supplemental materials 1). There were no substantive changes in the results found. As such, we maintain that these variables are valuable in capturing health need without contributing to overadjustment bias.

While there were statistically significant associations between payment methods used to fund prescription charges and all of the dependent variables considered, the magnitude of the associations for extreme polypharmacy was notably smaller than those in the polypharmacy models. In particular, the association between enrolment in the LTI scheme and extreme polypharmacy (both with and without supplement use) was not statistically significant at the $5 \%$ level. This may be due to a type II error, as the number of participants using the LTI scheme who reported extreme polypharmacy is small. Our results suggest that our findings are robust for polypharmacy, but that there is uncertainty around the association between LTI enrolment and extreme polypharmacy.

\section{Strengths and limitations}

Our analysis has a number of strengths. This study is the first to evaluate the relationship between payment methods used for prescription medications and the odds of reporting polypharmacy, while adjusting for a range of socioeconomic and health-related factors. Polypharmacy is an important and costly public health problem, and the results of our study provide new insight into this issue.

Second, we use data from a large, nationally representative cohort study that collects high-quality information on a range of key health, social and economic variables. Data collection is carried out by trained professionals in the participants' home environment, with participants providing the details of all the medications they consume on a regular basis. Thus, the estimates of polypharmacy used here are likely to be more reflective of total number of medicines actually consumed, as opposed to the use of medical or pharmacy records which may be prone to administrative error. Additionally, the use of the TILDA data set allows us to control for a range of relevant factors that have previously been found to be correlated with polypharmacy. This reduces the issue of confounding, strengthening our finding of an independent association between polypharmacy and payment methods for prescription charges.

A recognised limitation of our approach is the consideration of polypharmacy in quantitative terms alone. While the most commonly used definitions of polypharmacy use numerical measures, there is a growing body of evidence that suggests polypharmacy should be considered in qualitative terms. ${ }^{3}{ }^{17}$ Cadogan et al propose a distinction between 'appropriate polypharmacy' and 'inappropriate polypharmacy'. ${ }^{33}$ The argument follows that in many patients the use of a relatively large number of medications may be clinically appropriate and justified, and conversely, there may be a cohort of patients who use a relatively low amount of medications which may still be clinically superfluous. Notably, researchers who examined Irish data over a 15-year period found that although the overall polypharmacy rate was increasing, the relative rate of potentially inappropriate prescribing was decreasing. ${ }^{34}$ While the qualitative approach to measuring polypharmacy may provide a more refined measure of the issue, the measurement process poses a significant challenge when taken in the context of the available evidence. The majority of the data available in this area are observational, derived from population-based cohort studies or registry-based databases. While some methods have been proposed, determining clinical and medical need from these data in order to optimally discriminate between appropriate and inappropriate polypharmacy is not always feasible.

A further limitation is that the variable used to capture the presence of chronic illness was a binary variable which indicated if a participant reported having at least one chronic illness or disability. This means we were not able to consider the role of multimorbidity (defined as at least two chronic illnesses), which may be important since polypharmacy can be driven by drug-disease interactions or prescribing cascades. In addition, the variables used to account for health need in this analysis are selfreported. Therefore, we cannot guarantee that clinical need has been fully captured in our models. Finally, given the cross-sectional nature of our data and modelling approach, we have estimated the independent association between polypharmacy and payment method, as opposed to the causal relationship.

\section{Implications}

One implication of our results is that that the quantity of medications consumed by an individual may be influenced by payment methods for prescription fees. Incentives that increase the upfront cost faced by the patient at the point of use are often hypothesised to reduce utilisation rates, and vice versa. Therefore, it could be that schemes that provide individuals with free or heavily subsidised prescription medications result in higher relative medication consumption. This has potentially important efficiency and equity implications. On the one hand it could be that individuals who face relatively higher costs are constraining their medication intake due to financial barriers. On the other, it could be that individuals who receive free or heavily subsidised prescription charges may be consuming more medications than necessary, with little financial incentive to reduce consumption. Without knowing if polypharmacy is clinically appropriate or not, it is not possible to evaluate which effect is driving our results. In addition, the relationship observed may be explained by factors not included in the model. For 
example, greater levels of multimorbidity may increase an individual's chance of becoming eligible for entitlements to free or low-cost medications, while also increasing the likelihood that they would consume greater numbers of medications.

There are practical implications associated with our findings. First, we provide evidence that the majority of polypharmacy in older adults is concentrated among those who use publicly funded subsidies, namely the MC, DPS and LTI schemes. These schemes are under the remit of the PCRS, which compiles statistics on prescription drug use as part of the payment processing. Such data could be used to help disentangle appropriate and inappropriate polypharmacy, particularly if there was scope to link it to existing or planned clinical databases. Second, previous studies in Ireland have reported community-based interventions to be effective in reducing potentially inappropriate prescribing. ${ }^{35}$ The strong relationship between polypharmacy and higher GP visitation rates observed in this study supports the use of primary care-based interventions for targeting polypharmacy in older adults.

\section{CONCLUSION}

Payment methods for prescription drugs are independently associated with the likelihood of older adults in Ireland reporting polypharmacy. This suggests that enrolment in a scheme which provides free or heavily subsidised medications may lead to differential use of medications. However, our study was limited by an inability to discriminate between appropriate and inappropriate polypharmacy, or to account for differential levels of multimorbidity. Therefore, further research is needed to fully disentangle the relationship between polypharmacy and payment methods for prescription drugs in order to inform future healthcare policy in Ireland.

Twitter Aine Varley @varletron

Acknowledgements The authors would like to acknowledge the expertise and support provided by Professor Michael Barry during the study.

Contributors AV was the lead researcher and involved in the design, implementation, and analysis and reporting of the study. JC provided substantial contributions to the conception, design, analysis and reporting of the work. AV and $\mathrm{JC}$ have read and approved the final manuscript and agree to be accountable for all aspects of the work.

Funding The authors have not declared a specific grant for this research from any funding agency in the public, commercial or not-for-profit sectors.

Competing interests None declared.

Patient consent for publication Not required.

Ethics approval Ethical approval for the TILDA study was received from the Trinity College Research Ethics Committee and all participants provided written informed consent. TILDA has both publicly available data, which can be accessed as described in the section 'Data sharing', as well as additional data that are available only for research purposes.

Provenance and peer review Not commissioned; externally peer reviewed.

Data availability statement Data are available in a public, open access repository. Researchers interested in using TILDA data may access the data for free from the following sites: Irish Social Science Data Archive (ISSDA) at University College Dublin, www.ucd.ie/issda/data/tilda/; Interuniversity Consortium for Political and
Social Research (ICPSR) at the University of Michigan, http://www.icpsr.umich.edu/ icpsrweb/ICPSR/studies/34315.

Open access This is an open access article distributed in accordance with the Creative Commons Attribution Non Commercial (CC BY-NC 4.0) license, which permits others to distribute, remix, adapt, build upon this work non-commercially, and license their derivative works on different terms, provided the original work is properly cited, appropriate credit is given, any changes made indicated, and the use is non-commercial. See: http://creativecommons.org/licenses/by-nc/4.0/.

ORCID iD

Aine Varley http://orcid.org/0000-0002-3698-0341

\section{REFERENCES}

1 Montamat SC, Cusack B. Overcoming problems with polypharmacy and drug misuse in the elderly. Clin Geriatr Med 1992;8:143-58.

2 Royal Pharmaceutical Society. Polypharmacy: getting our medicines right. Available: https://www.rpharms.com/recognition/settingprofessional-standards/polypharmacy-getting-our-medicines-right [Accessed 7 Oct 2019].

3 Masnoon N, Shakib S, Kalisch-Ellett L, et al. What is polypharmacy? A systematic review of definitions. BMC Geriatr 2017;17:1-10.

4 Maher RL, Hanlon J, Hajjar ER. Clinical consequences of polypharmacy in elderly. Expert Opin Drug Saf 2014;13:57-65.

5 Moßhammer D, Haumann H, Mörike K, et al. Polypharmacyan upward trend with unpredictable effects. Dtsch Arztebl Int 2016;113:627-33.

6 Routledge PA, O'Mahony MS, Woodhouse KW. Adverse drug reactions in elderly patients. Br J Clin Pharmacol 2004;57:121-6.

7 Hovstadius B, Petersson G. The impact of increasing polypharmacy on prescribed drug expenditure-a register-based study in Sweden 2005-2009. Health Policy 2013;109:166-74.

8 Wu C, Bell CM, Wodchis WP. Incidence and economic burden of adverse drug reactions among elderly patients in Ontario emergency departments: a retrospective study. Drug Saf 2012;35:769-81.

9 Roebuck MC, Liberman JN, Gemmill-Toyama M, et al. Medication adherence leads to lower health care use and costs despite increased drug spending. Health Aff 2011;30:91-9.

10 Guthrie B, Makubate B, Hernandez-Santiago V, et al. The rising tide of polypharmacy and drug-drug interactions: population database analysis 1995-2010. BMC Med 2015;13:1-10.

11 Slater N, White S, Venables R, et al. Factors associated with polypharmacy in primary care: a cross-sectional analysis of data from the English longitudinal study of ageing (ELSA). BMJ Open 2018;8:e020270-9.

12 Morin L, Johnell K, Laroche M-L, et al. The epidemiology of polypharmacy in older adults: register-based prospective cohort study. Clin Epidemiol 2018;10:289-98.

13 Payne RA, Avery AJ, Duerden M, et al. Prevalence of polypharmacy in a Scottish primary care population. Eur J Clin Pharmacol 2014;70:575-81.

14 Haider SI, Johnell K, Weitoft GR, et al. The influence of educational level on polypharmacy and inappropriate drug use: a registerbased study of more than 600,000 older people. J Am Geriatr Soc 2009;57:62-9.

15 Hanlon P, Nicholl BI, Jani BD, et al. Examining patterns of multimorbidity, polypharmacy and risk of adverse drug reactions in chronic obstructive pulmonary disease: a cross-sectional UK Biobank study. BMJ Open 2018;8:e018404.

16 Payne RA. The epidemiology of polypharmacy. Clin Med 2016;16:465-9.

17 Fried TR, O'Leary J, Towle V, et al. Health outcomes associated with polypharmacy in community-dwelling older adults: a systematic review. J Am Geriatr Soc 2014;62:2261-72.

18 Richardson K, Moore P, Peklar J, et al. Polypharmacy in adults over 50 in Ireland: opportunities for cost saving and improved healthcare. Irish Longitud Study Aging 2012.

19 United Nations. World population ageing. New York, 2017.

$20 \mathrm{He} \mathrm{W}$, Goodkind D, Kowal P. An aging world: 2015. US census Bur int Popul reports, 2016: 1-175.

21 Central Statistics Office. Population and Labour Force Projections 2016 - 2051, 2017. Available: https://www.cso.ie/en/releasesandp ublications/ep/p-plfp/populationandlabourforceprojections20172051/

22 Rawle MJ, Richards M, Davis D, et al. The prevalence and determinants of polypharmacy at age 69: a British birth cohort study. BMC Geriatr 2018;18:1-12. 
23 Nolan A, Smith S. The effect of differential eligibility for free GP services on GP utilisation in Ireland. Soc Sci Med 2012;74:1644-51.

$24 \mathrm{Ma} \mathrm{Y}$, Nolan A. Public healthcare Entitlements and healthcare utilisation among the older population in Ireland. Health Econ 2017;26:1412-28.

25 Tatum T, Curry P, Dunne B, et al. Polypharmacy rates among patients over 45 years. Ir Med J 2019;112:893.

26 Kearney PM, Cronin H, O'Regan C, et al. Cohort profile: the Irish longitudinal study on ageing. Int J Epidemiol 2011;40:877-84.

27 Whelan BJ, Savva GM. Design and methodology of the Irish longitudinal study on ageing. J Am Geriatr Soc 2013;61 Suppl 2:S265-8.

28 Cronin H, O'Regan C, Finucane C, et al. Health and aging: development of the lrish longitudinal study on ageing health assessment. J Am Geriatr Soc 2013;61 Suppl 2:S269-78.

29 Miilunpalo S, Vuori I, Oja P, et al. Self-Rated health status as a health measure: the predictive value of self-reported health status on the use of physician services and on mortality in the working-age population. J Clin Epidemiol 1997;50:517-28.
30 McGee DL, Liao Y, Cao G, et al. Self-Reported health status and mortality in a multiethnic US cohort. Am J Epidemiol 1999;149:41-6.

31 Luo N, Johnson JA, Shaw JW, et al. Self-Reported health status of the general adult U.S. population as assessed by the EQ-5D and health Utilities index. Med Care 2005;43:1078-86.

32 Wimmer BC, Cross AJ, Jokanovic N, et al. Clinical outcomes associated with medication regimen complexity in older people: a systematic review. J Am Geriatr Soc 2017;65:747-53.

33 Cadogan CA, Ryan C, Hughes CM. Appropriate polypharmacy and medicine safety: when many is not too many. Drug Saf 2016;39:109-16.

34 Moriarty F, Hardy C, Bennett K, et al. Trends and interaction of polypharmacy and potentially inappropriate prescribing in primary care over 15 years in Ireland: a repeated cross-sectional study. BMJ Open 2015;5:e008656.

35 Clyne B, Smith SM, Hughes CM, et al. Effectiveness of a multifaceted intervention for potentially inappropriate prescribing in older patients in primary care: a cluster-randomized controlled trial (OPTI-SCRIPT study). Ann Fam Med 2015;13:545-53. 